\title{
FUZZY NUMBERS BASED ON ENERGY INDICATORS OF RELIABILITY POWER SYSTEM
}

\author{
${ }^{1}$ Nadheer A. Shalash and ${ }^{2}$ Abu Zaharin Ahmad \\ ${ }^{1}$ Faculty of Engineering of Electrical power techniques \\ Al-Mamon University college, \\ Baghdad, Iraq \\ ${ }^{2}$ Faculty of Electrical and Electronics Engineering \\ University Malaysia Pahang, \\ 26600 Pekan, Malaysia
}

\begin{abstract}
This paper presents the approach of fuzzy numbers for reliability calculation of electrical energy indices and compared to an analytical method. In this paper, the fuzzy numbers which are represented by triangular fuzzy numbers are used to evaluate the load duration curve and the probabilities capacity generators that are in services, in term of the expected energy not supplied (EENS), loss of energy expectation (LOEE) and the energy index of the reliability (EIR). A case study based on the Malaysia distribution network (DISCO-Net) is carried out.The proposed method shows a simple implementation and the results seem to be a good approximation to the analytical approach.
\end{abstract}

\section{Keywords}

Electrical energy indice; fuzzy numbers; daily load; Probability.

\section{INTRODUCTION}

Recently, many applications of the fuzzy numbers approach to electric power system engineering have been proposed. One of these applications is assessed on reliability generation based on the loss of energy indices. Reliability of the generated power system is afflicted with the load curve characteristics, peak duration and variety between levels of the peak at each hour, day and month of each season of a year. Various kinds of customers might have different load curve charts. The most frequent for electrical loads are for residential, commercial and industrial, which isfor each load curve usually contains a characteristic chart. Probability based models have already been advanced for precisely reflects the stochastic nature of generators behavior and determines its reliability interpretation [1-2]. As a result of the increased demand powers, a small separated system is not able to provide a power with sufficient generation control and an acceptable level of DOI : $10.14810 /$ elelij.2016.5205 
reliability at hierarchical level I (HL-I). This includes the ability of the generation to meet the total system load requirement [3] and to have the reserve margin capacity in order to serve for planned and forced outage events. It is also must be able to accurately meet up with the large fluctuations in the load from the result of a different quantity of power users[4, 17].

Power system reliability can be divided into two aspects, i.e., adequacy and security. System adequacy is related to the existing of appropriate generators within the system to cater the demand or the operational constraints and also to have an excess capacity to cater for planned and forced outage events that depended on the area under the load duration curve. In this paper, most widely used indices in electrical energy is presented, i.e., Loss of Energy Expectation (LOEE), Expected Energy Not Supplied (EENS) and the Energy Index of Load Reliability (EIR).

In [5],has presented a new fuzzy operationfor the area under the load duration curve model for evaluating reliability indices of composite power systems based on probability and fuzzy set methods.Meanwhile, in [6] has used fuzzy load description in generation, transmission power system reliability that using Monte Carlo method. A new hybrid approach to evaluate a generation system reliability using a fuzzy clustering approach in modeling the loads has been presented in [7]. Then, in [8] had proposed a genetic algorithm guided by fuzzy numbers to evaluate the power system reliability.

Hence, motivated by the reviews, this paper is tend to proposein the application of a fuzzy numbers approach to energy indices of power system based on the LOEE, EENS and EIR analysis. The proposed technique is then tested by using Malaysia distribution network (DISCONet) in MATLAB environment. The test results show by comparing the proposed technique with analytical method in order to help the engineers to measure and make decisions for assessment reliability power system.

\section{ENERGY RELIABILITY INDICES}

The most common methods used for reliability evaluation, are based on the loss of load or energy approach. In this method, the suitability index that describes generation reliability level is loss of energy expectation.It can be calculated the area under the load duration curve.It also indicates the time in which the load is more than available generation and can be used to calculate an expected energy not supplied [9,19]. In [10], By Billinton and Li (1994), The basic expected energy curtailed concept can also be used to determine the expected energy produced by each unit in the system and therefore provides a relatively simple approach to production cost modelling.

$E E N S=\sum_{i=S} P_{i}\left(C_{S}\right)$

Where, $\mathrm{S}$ : set of all possible system states associated with loss of load, $\mathrm{C}_{\mathrm{s}}$ : Capacity in service, Dns: demand not supplied of state $i$.

The probable energy curtailed is obtained as a production of a probability of capacity in outage $\left(\mathrm{P}_{\mathrm{i}}\right)$ and the energy curtailed by capacity in outage $\left(\mathrm{E}_{\mathrm{i}}\right)$. The sum of these givesthe total loss of energy expectation (LOEE) $[9,11,19]$.

$$
\text { LOEE }=\sum_{i=1}^{n} E_{i} P_{i}
$$


After that, it can be normalized the loss of energy expectation by using the total energy under the load duration curvedesignated as E in Equation (3).

$L O E E_{\%}=\sum_{i=1}^{n} \frac{E_{i} P_{i}}{E}$

Future electrical power systems may be energy limited rather than power or capacity limited, so we will study the ratio between the probable load energy curtailed because of reduced capacity because of specific capacity in outage and the total energy under the load duration curve can be defined as an energy index of unreliability. The energy index of reliability (EIR) is then as follows [11]:

$E I R=1-L O E E_{\%}$

\section{FUZZY NUMBER}

The arranging of fuzzy numbers plays an important role in decision making and optimization in power system reliability. The fuzzy approach must be derived before an action is taken by an engineer. In this paper, the special class of fuzzy numbers for load called triangular fuzzy numbers is used $[12,16]$.The fuzzy set $\mathrm{G}$ is called a normal fuzzy set. A fuzzy number is a fuzzy method in the load that is both convex and normal. A type of fuzzy number of the load can be characterized by a triangular membership function parameterized by a triplet (L1, L2, L3), as shown in Fig. 1 [13].

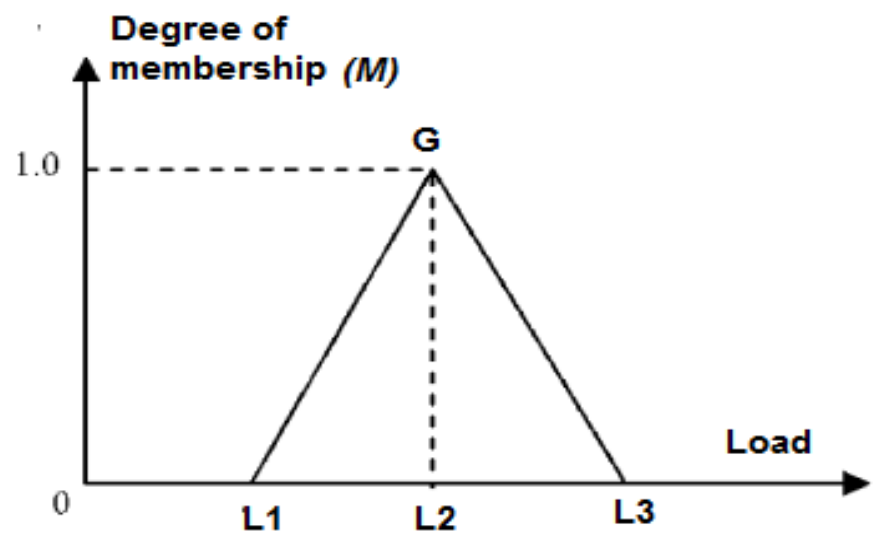

Figure 1. Triangular membership function

The membership function is defined in mathematical form as follows: 


$$
\mu L(x)=\left\{\begin{array}{lc}
0 & x<L_{1} \\
\frac{x-L_{1}}{L_{2}-L_{1}} L_{1} \leq x \leq L_{2} \\
\frac{L_{3}-x}{L_{3}-L_{2}} L_{2} \leq x \leq L_{3} \\
0 & x>L_{3}
\end{array}\right.
$$

Where xisa load duration curve.

\section{PROPOSED METHOD}

In this section, the proposed approach to electrical energy indicesevaluation is presented which takes the load duration under curve with probabilities capacity outage using a new fuzzy evaluation sheet.As an example, a generation system consists of $3 \times 20 \mathrm{MW}$, that means, the estimation is based on 4 selected capacity outage as namely the generation $0,20,40$ and $60 \mathrm{MW}$ with identical weights of each state is $w 1, w 2, w 3$ and w4 respectively, where wi $\in[0,1]$ and $i=$ $1,2,3$ and 4 . The value of the weight will be determined the degree of membership that obedience to load levels (Ls) and the probability (P1, P2, P3and P4) as shown in Fig. 2.

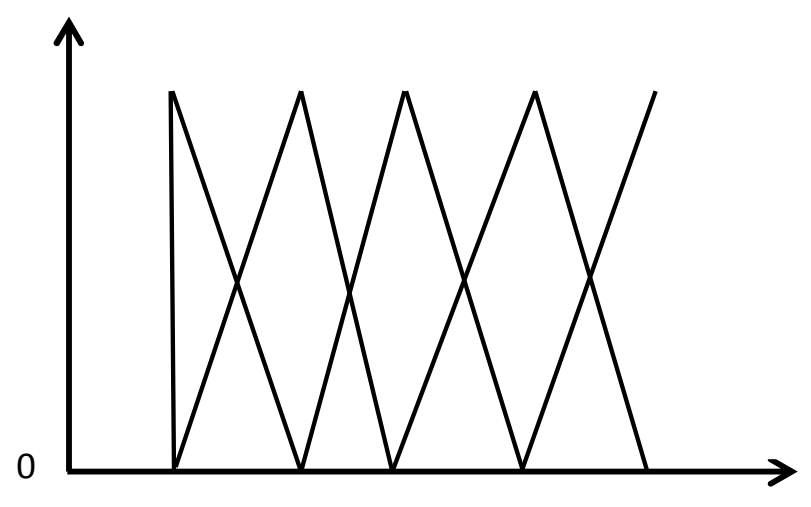

Figure 2. Triangular membership function for load level

Each fuzzy load number is defined by three values of load to usetriangular fuzzy numbers $[14,16]$ comprehensive effects of transmission line [18]. In Table I, The fuzzy numbers offered ten satisfaction levels in addition, area percentage of loads and the maximum degree of membership. Fainlly, the fuzzy evaluation sheet has four state $(\mathrm{C} 1, \mathrm{C} 2, \mathrm{C} 3, \mathrm{C} 4)$ for capacity in service as shown in Table II. 
Electrical and Electronics Engineering: An International Journal (ELELIJ) Vol 5, No 2, May 2016

Table I

Level of Load and Their Identical Degree of Load

\begin{tabular}{|c|c|c|}
\hline Level of Load & $\begin{array}{c}\text { Degree of Load } \\
\text { (Ls) }\end{array}$ & $\begin{array}{c}\text { Maximum degree of } \\
\text { membership }\end{array}$ \\
\hline $100 \%$ load & $100 \%$ & 1 \\
\hline $90 \%$ load & $81 \%-99 \%$ & 0.9 \\
\hline $80 \%$ load & $71 \%-80 \%$ & 0.8 \\
\hline $70 \%$ load & $61 \%-70 \%$ & 0.7 \\
\hline $60 \%$ load & $51 \%-60 \%$ & 0.6 \\
\hline $50 \%$ load & $41 \%-50 \%$ & 0.5 \\
\hline $40 \%$ load & $31 \%-40 \%$ & 0.4 \\
\hline $30 \%$ load & $20 \%-30 \%$ & 0.3 \\
\hline $20 \%$ load & $1 \%-19 \%$ & 0.2 \\
\hline $0 \%$ load & $0 \%$ & 0.0 \\
\hline
\end{tabular}

Table II New Fuzzy Evaluation Sheet

\begin{tabular}{|c|c|c|c|c|c|c|c|c|c|}
\hline \multirow{2}{*}{$\begin{array}{l}\text { Capacit } \\
y \text { in } \\
\text { service }\end{array}$} & \multirow{2}{*}{$\begin{array}{l}\text { L } \\
\text { o } \\
\text { a } \\
\text { d } \\
\text { s } \\
\end{array}$} & \multirow{2}{*}{$\begin{array}{c}\text { We } \\
\text { igh } \\
\text { ts }\end{array}$} & \multicolumn{4}{|c|}{ Load levels } & \multirow{2}{*}{$\begin{array}{l}\text { Degre } \\
\text { e of } \\
\text { Satisf } \\
\text { action } \\
\text { (Ls) }\end{array}$} & \multirow{2}{*}{$\begin{array}{c}\text { Fuzz } \\
\mathbf{y} \\
\text { load } \\
(\mathbf{F l})\end{array}$} & \multirow{2}{*}{$\begin{array}{c}\text { Pr } \\
\text { ob } \\
\text { abi } \\
\text { lity }\end{array}$} \\
\hline & & & $10 \%$ & $30 \%$ & $60 \%$ & $100 \%$ & & & \\
\hline $\mathrm{C} 1=0$ & & W1 & $\mathrm{d} 1$ & $\mathrm{~d} 2$ & d3 & $\mathrm{d} 4$ & & & P1 \\
\hline $\mathrm{C} 2=20$ & & W2 & & & & & & & $\mathrm{P} 2$ \\
\hline $\mathrm{C} 3=40$ & & W3 & & & & & & & P3 \\
\hline$C 4=60$ & & W4 & & & & & & & P4 \\
\hline \multirow{2}{*}{$\begin{array}{c}\text { Capacit } \\
y \text { in } \\
\text { service }\end{array}$} & \multirow{2}{*}{\begin{tabular}{l|}
$\mathrm{L}$ \\
$\mathrm{o}$ \\
$\mathrm{a}$ \\
$\mathrm{d}$ \\
$\mathrm{s}$
\end{tabular}} & \multirow{2}{*}{$\begin{array}{c}\text { We } \\
\text { ight } \\
\text { s }\end{array}$} & \multicolumn{4}{|c|}{ Load levels } & Degre & Fuzz & Pro \\
\hline & & & $10 \%$ & $30 \%$ & $60 \%$ & $100 \%$ & $\begin{array}{c}\text { Satisfa } \\
\text { ction } \\
\text { (Ls) }\end{array}$ & $\begin{array}{c}\mathrm{y} \\
\text { load } \\
(\mathrm{Fl})\end{array}$ & $\begin{array}{c}\text { bab } \\
\text { ilit } \\
y\end{array}$ \\
\hline $\mathrm{C} 1=0$ & & W1 & $\mathrm{d} 1$ & d2 & d3 & $\mathrm{d} 4$ & & & P1 \\
\hline $\mathrm{C} 2=20$ & & W2 & & & & & & & $\mathrm{P} 2$ \\
\hline $\mathrm{C} 3=40$ & & W3 & & & & & & & P3 \\
\hline $\mathrm{C} 4=60$ & & W4 & & & & & & & P4 \\
\hline
\end{tabular}

The degree of satisfaction of the load (Ls) is calculated by equation (6) :

$$
L s=\frac{d_{1} * 10 \%+d_{2} * 20 \%+d_{3} * 30 \%+d_{4} * 40 \%}{d_{1}+d_{2}+d_{3}+d_{4}}
$$


Where, $\mathrm{d}_{\mathrm{k}} \in[0,1]$ is a degree of fuzzy load and $1 \leq \mathrm{k} \leq 4$, The fuzzy load $(F l)$ for every state can be calculated by Equation (7):

$$
F l=L s_{i} * \operatorname{load}{ }_{\mathrm{i}}
$$

Where, Load I = load demand, which requires an evaluation of the determined capacity in service, including larger values of capacity in service.

The demand not supplied (Dns) it is equal to energy curtailed by capacity in service. When the fuzzy load applied to implement the (Dns) this will result into the Equation (8):

Dns $=\left(I_{L T}-F I\right) * h=E_{i}-F I^{*} h$

Where, $I_{L T}$ : total load demand under the load duration curve, h: the duration of load power in hours.

The equations in section II above, i.e (1), (3) and (4) were used to assess losses of energy indices without fuzzy, in the subsequent Equations (9), (10) and (11), fuzzy load duration curve shall be used to evaluate these indices.

$$
\begin{aligned}
& \text { EENS }=\sum_{\mathrm{i} \in \mathrm{s}} \mathrm{p}_{\mathrm{i}}\left(\mathrm{C}_{\mathrm{s}}\right) *\left(\mathrm{E}_{\mathrm{i}}-\mathrm{FI} * \mathrm{~h}\right) \\
& \text { LOEE }=\sum_{\mathrm{i} \in \mathrm{s}} \text { EENS } \\
& \text { EIR }=1-\frac{\text { LOEE }}{\mathrm{E}}
\end{aligned}
$$

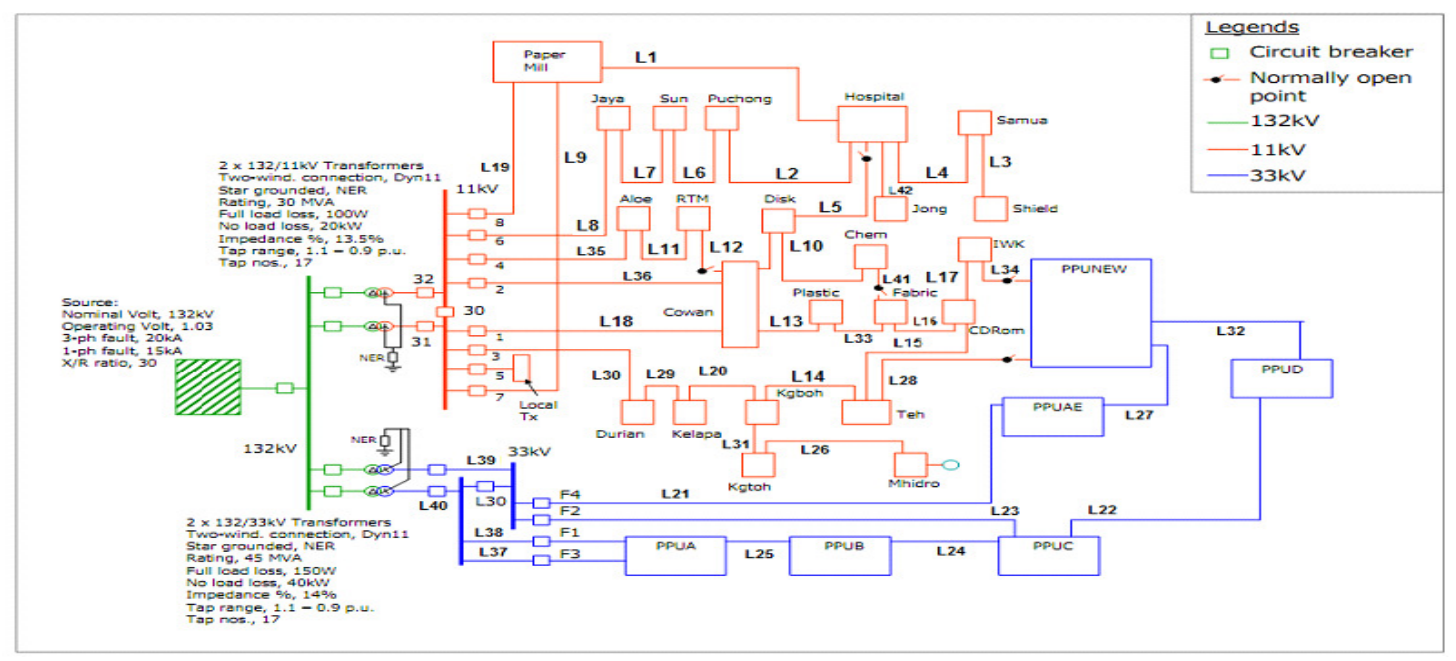

Figure 3: Single line diagram of Malaysia network of DISCO-Net power system 
Electrical and Electronics Engineering: An International Journal (ELELIJ) Vol 5, No 2, May 2016

Table III

The data of generating units and transmission line (Network of DISCO-Net)

\begin{tabular}{|l|c|c|c|c|c|}
\hline \multicolumn{1}{|c|}{ Parameters } & No. & $\lambda$ (occ./year) & $\begin{array}{c}\mu \\
\text { (hrs) }\end{array}$ & $\begin{array}{c}\text { Unit } \\
\text { failure } \\
\text { probab. }\end{array}$ & $\begin{array}{c}\text { Unit } \\
\text { success } \\
\text { probab. }\end{array}$ \\
\hline G1 & 2 & 2 & 98 & 0.1 & 0.9 \\
\hline DG & 1 & 2 & 98 & 0.1 & 0.9 \\
\hline L1, L2, L3, L4, L5 & 2 & 2 & 98 & 0.1 & 0.9 \\
\hline L6, L7, L8, L9, L10 & 3 & 2 & 98 & 0.1 & 0.9 \\
\hline L11, L12, L13, L14 & 2 & 0.03 & 98 & 0.2 & 0.8 \\
\hline L17, L18, L19, L20 & 3 & 0.09 & 98 & 0.2 & 0.8 \\
\hline L21, L22, L23, L24 & 3 & 0.2 & 0.5 & 0.2 & 0.8 \\
\hline L27, L28, L29 & 2 & 0.28 & 0.5 & 0.2 & 0.8 \\
\hline L31, L32, L33, L34 & 2 & 0.23 & 0.5 & 0.2 & 0.8 \\
\hline L35, L42, L41 & 2 & 0.01 & 0.5 & 0.2 & 0.8 \\
\hline L15, L16, L25, L26 & 2 & 0.09 & 0.5 & 0.2 & 0.8 \\
\hline L39, L40 & 2 & 0.15 & 0.5 & 0.2 & 0.8 \\
\hline L30, L38, 137 & 2 & 0.25 & 0.5 & 0.2 & 0.8 \\
\hline
\end{tabular}

\section{DESCRIPTION OF TEST SYSTEM}

The step down substation (in Malaysia is called main intake substation) is connected to the grid at nominal voltage of $132 \mathrm{kV}$. The maximum 3-phase and 1-phase-to-ground fault currents at the source are illustrated in Fig. 3 which means that on a 3-phase solid fault of the $132 \mathrm{kV}$ bus, the fault current, which is contributed by the source, is $20 \mathrm{kA}$ and $15 \mathrm{kA}$ on a single-phase to ground fault. The $132 \mathrm{kV}$ is stepped down to $11 \mathrm{kV}$ using $2 \times 30 \mathrm{MVA}$ transformers and to $33 \mathrm{kV}$ using 2x45MVA transformers whose parameters are also illustrated in Fig. 3 (Network of DISCO-Net) [15]. This system has 33 buses with a 32 load bus, 45 transmission lines and 2 generating units $2 \mathrm{x} 75 \mathrm{MW}$. The total installed generating capacity is $150 \mathrm{MW}$ and the peak load of the system is 120MW. The data of generating units are given in Table III.This system was selected as a case study to implement the developed coding in order to analysis and determine electrical energy indices by fuzzy numbers and compared to an analytical method. 
Electrical and Electronics Engineering: An International Journal (ELELIJ) Vol 5, No 2, May 2016

Figure 4: Load duration curve for DISCO-Net

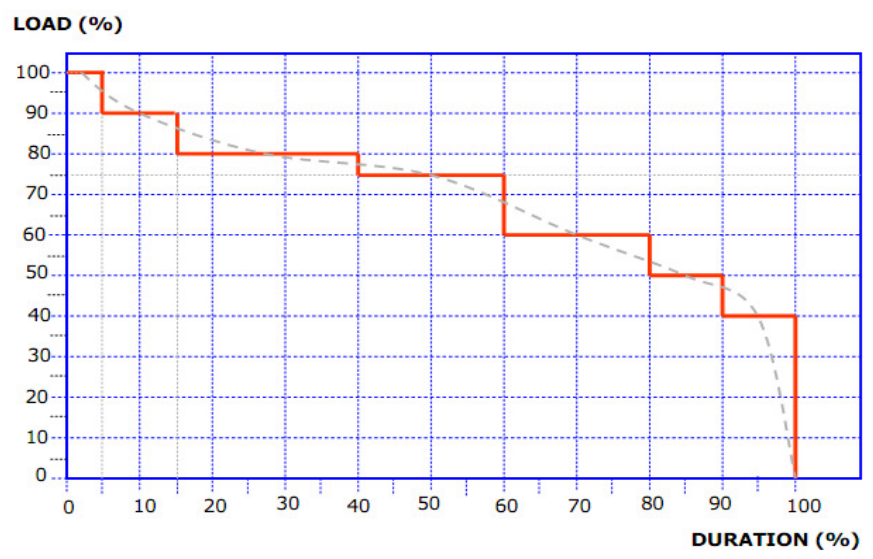

Table III: Analytical method to Calculate EENS with unit 1

\begin{tabular}{|c|c|c|c|c|}
\hline $\begin{array}{c}\text { Capacity } \\
\text { out service } \\
\text { (MW) }\end{array}$ & $\begin{array}{c}\text { Capacity in } \\
\text { service } \\
\text { (MW) }\end{array}$ & Probability & $\begin{array}{c}\text { Energy } \\
\text { MWh }\end{array}$ & EENS \\
\hline $\mathbf{0}$ & 150 & 0.5314 & 0 & 0 \\
\hline $\mathbf{2 5}$ & 125 & 0.059 & 0 & 0 \\
\hline $\mathbf{5 0}$ & 100 & 0.00656 & 2440 & 16.0064 \\
\hline $\mathbf{7 5}$ & 75 & 0.000729 & 3940 & 2.87226 \\
\hline $\mathbf{1 0 0}$ & 50 & 0.000081 & 4440 & 0.35964 \\
\hline $\mathbf{1 2 5}$ & 25 & 0.000009 & 5940 & 0.05346 \\
\hline $\mathbf{1 5 0}$ & 0 & 0.000001 & 8440 & 0.00844 \\
\hline
\end{tabular}

Table IV Analytical Method To Calculate Eens With Units $1 \& 2$

\begin{tabular}{|c|c|c|c|c|}
\hline $\begin{array}{c}\text { Capacity out } \\
\text { service (MW) }\end{array}$ & $\begin{array}{c}\text { Capacity in } \\
\text { service (MW) }\end{array}$ & Probability & $\begin{array}{c}\text { Energy } \\
\text { MWh }\end{array}$ & EENS \\
\hline $\mathbf{0}$ & 75 & 0.729 & 3940 & 2872.26 \\
\hline $\mathbf{2 5}$ & 50 & 0.0891 & 4440 & 395.604 \\
\hline $\mathbf{5 0}$ & 25 & 0.009 & 5940 & 53.46 \\
\hline $\mathbf{7 5}$ & 0 & 0.001 & 8440 & 8.44 \\
\hline
\end{tabular}




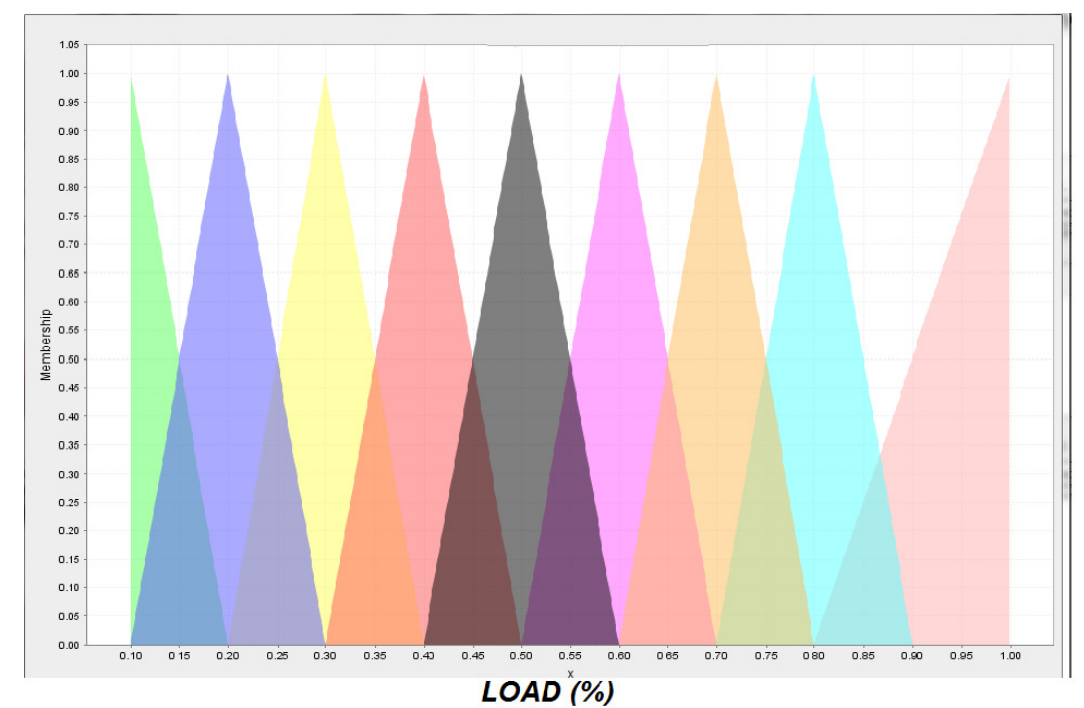

Figure 4. Load duration curve for DISCO-Net

Table VI New Fuzzy Evaluation For Disco-Net

\begin{tabular}{|c|c|c|c|c|c|c|c|c|c|c|c|c|c|c|}
\hline \multirow{2}{*}{$\begin{array}{c}\text { Capacity } \\
\text { in } \\
\text { service }\end{array}$} & \multirow{2}{*}{ Load } & \multirow{2}{*}{ Weights } & \multicolumn{7}{|c|}{ Load levels } & \multirow{2}{*}{$\begin{array}{c}\text { Degree of } \\
\text { satisfaction }\end{array}$} & \multirow{2}{*}{$\begin{array}{l}\text { Fuzzy } \\
\text { load }\end{array}$} & \multirow{2}{*}{$\begin{array}{c}\text { Fuzzy } \\
\text { Probability }\end{array}$} & \multirow{2}{*}{ Energy } & \multirow{2}{*}{ EENS } \\
\hline & & & L1 & L2 & L3 & $\mathrm{L} 4$ & L5 & L6 & L7 & & & & & \\
\hline 100 & 80 & 0.8 & 0 & 0 & 0 & 0 & 0.4 & 0.56 & 0.97 & 0.84 & 84 & 0.00656 & 2145 & 14.0712 \\
\hline 75 & 55 & 0.73 & 0 & 0 & 0 & 0 & 0.42 & 0.82 & 0.52 & 0.78 & 58.5 & 0.000729 & 3565 & 2.598 \\
\hline 50 & 35 & 0.7 & 0 & 0 & 0 & 0 & 0.56 & 0.93 & 0.42 & 0.72 & 36 & 0.000081 & 4195 & 0.3398 \\
\hline 25 & 16 & 0.64 & 0 & 0 & 0 & 0.35 & 0.82 & 0.65 & 0.22 & 0.68 & 17 & 0.000009 & 5545 & 0.0499 \\
\hline 0 & 0 & 0 & 0 & 0 & 0 & 0 & 0 & 0 & 0 & N/A & 0 & 0.000001 & 8440 & 0.00844 \\
\hline & & & & & & & & & & & & $\begin{array}{l}\text { Total } \\
\text { EENS } \\
\end{array}$ & & 17.067 \\
\hline
\end{tabular}

\section{RESULT AND DISCUSSION}

First, in this study estimate, load duration curve for DISCO-Net is shown in Fig. 4. The total required energy in this duration is $8440 \mathrm{MWh}$. If there is no generation in the system, the expected energy not supplied would be $8440 \mathrm{MWh}$ when the system has $75 \mathrm{MW}$.Table IV is shown an analytical method for the EENS with Unit 1, the value of expected energy not supplied is equal $(2872.26+395.604+53.46+8.44)$ and the expected energy by unit $(1)=8440-3329.764$ $=5110.236 \mathrm{MWh}$. From these results the energy index of the reliability EIR by unit (1) is 0.605478 . The assistance from unit (2) can be obtained by adding $75 \mathrm{MW}$ to the generation units 
Electrical and Electronics Engineering: An International Journal (ELELIJ) Vol 5, No 2, May 2016

of the Table IV and resulting the expected energy not supplied for units (1) and (2) integrated (see Table V).In this case, the total EENS $=19.3$ and the expected energy by unit (2) is 5090.933 MWh.Finally, we can calculate EIR for the system using Equation(4), i.e.,EIR=1-(19.3/8440) = 0.9977132 .

Then, second proposedof the fuzzy number to compare the calculating results of the reliability energy indexes with analytical method.The fuzzy number has one membershipconsidering triangular fuzzy numbers for load duration curve shown in Fig.5.

For example, the column weights value in the Table $\mathrm{V}$ is obtained by simply dividing load with capacity in service, i.e.,80/100 $=0.8$. This value 0.8 , will then determine the degree of membership corresponding to the probabilities levels, from the results obtained in Table VI, the values, $0,0,0,0,0.4,0.56,0.79$ denotes the load level values at L1-L7 respectively. The values of energy and EENS were calculated with equations 6 and 7 which are the fuzzy load set that uses the central of the area. From table IV below, the same simulation was applied to the subsequent load levels, the EENS for each stage obtained were summed up to get 17.067 otherwise referred to herein as defuzzification value, thus denoting the expected energy not supplied.

From this result, the energy index of the reliability EIR is 0.997977 derived from equation 9 . Conclusively, it is clearly shown that the result obtained with the use of EIR by fuzzy as energy indices assessment is close to the one derived when analytical method was used for same assessment.

\section{CONCLUSION}

This paper has been presented the application of a fuzzy numbers method to evaluate energy reliability indices based on a load duration curve and probabilities the capacity generators in service and compared with an analytical method in term of the expected energy not supplied and the energy index of the reliability for each state. It seems to be more near compared to results used in analytical approach.Therefore, this paper can help engineers to measure the reliability power system and make decisionsfor future process generation expansion planning.

\section{REFERENCES}

[1] Sidney J.Yakowitz.Computational Probability and Simulation. 3rd ed. Addison- Wesley Publishing Company: London; 1989.

[2] R. E. Brown. Electric Power Distribution Reliability. 2nd ed. New York: Marcel Dekker; 2002.

[3] Wijarn Wangdee. Bulk electric system reliability simulation and application. PhD thesis. Department of Electrical Engineering, University of Saskatchewan, Canada S7N 5A9, 2006.

[4] Devendra K. Chaturvedi. Soft Computing Techniques and its Applications in Electrical Engineering.Vol 103. Springer-Verlag Berlin Heidelberg, 2008.

[5] Choi ,J. et al. ,A study on the fuzzy ELDC of a composite power system based on probabilistic and fuzzy set theories, IEEE power Engineering society summer meeting ,2002, vol .3,pp.1123_1129.

[6] Saraiva ,J.T.et al., Generation /transmission power system reliability evaluation by monte carlo simulation assuming a fuzzy load description, IEEE Trans,1996,,Vol.2 , pp.690_695.

[7] Narasimhan, S.and Asgarpoor ,S., Including uncertainty in LOLE calculation using fuzzy set theory , IEEE Trans. On power systems,2000, Vol.45, pp.133_138. 
Electrical and Electronics Engineering: An International Journal (ELELIJ) Vol 5, No 2, May 2016

[8] Samaan , N. and Singh, C., state evaluation in composite power system reliability using genetic algorithm guided by fuzzy constraints in proceedings of the international conf.,2002, Vol.1,pp.409_414.

[9] Billinton, R. and R. Allan, 1996. Reliability Evaluation of Power Systems. Second Edition.New York: Plenum Press 2002.

[10] Billinton, R. and W. Li, Reliability assessement of electrical power system using Monte Carlo Methods, Springer, New York, 1994.

[11] Marko C epin. Assessment of power system reliability methods and applications. SpringerVerlag;2011.

[12] A.K.Verma, A.Srividya and R.Sprabhu. Fuzzy reliability Engineering, . New Delhi ,Narosa, 2007.

[13] Kaufmann,A, Introduction to the theory of fuzzy Subsets ,Vol.1, NEW York, 1975.

[14] H.-J. Zimmermann, Fuzzy Set Theory and Its Applications. Dordrecht, The Netherlands: KluwerNijhoff, 1991.

[15] "Electrical Power System Competition 2009 “ EPSCOM 2009, 40675 Shah Alam, Selangor 2009 in January 2009 at Universiti Kebangsaan Malaysia.

[16] Shalash, Nadheer A., and Abu Zaharin Ahmad. " Agents for fuzzy indices of reliability power system with uncertainty using Carlo algorithm." Power Engineering and Optimization Conference (PEOCO), 2014 pp. 258 - 264. IEEE, 24-25 March 2014.

[17] Vladislav O., Svyatoslav T. , Anna B. and Sergey Gusev."Stochastic Network Reduction Technique for Calculations of Electrical Power System Structural Reliability " Second International Symposium on Stochastic Models in Reliability Engineering (SMRLO), pp. 144 - 149. IEEE, 15-18 $\mathrm{Feb}$ 